\title{
The effects of a parasitoid wasp of a gall-making insect on host plant characteristics and the abundance of sharing host-plant herbivore
}

\author{
ANANTO TRIYOGO ${ }^{1, \bullet}$, HIRONORI YASUDA ${ }^{2}$ \\ ${ }^{1}$ Department of Silviculture, Faculty of Forestry, Universitas Gadjah Mada. Jl. Agro No 1, Bulaksumur, Sleman 55281, Yogyakarta, Indonesia. \\ Tel./fax.+62-274-512102, ‘email: triyogo99@yahoo.com. \\ ${ }^{2}$ Faculty of Agriculture, Yamagata University. 4-12 Kojirakawamachi, Yamagata, 990-8560, Japan
}

Manuscript received: 2 October 2019. Revision accepted: 9 November 2019.

\begin{abstract}
Triyogo A, Yasuda H. 2019. The effects of a parasitoid wasp of a gall-making insect on host plant characteristics and the abundance of sharing host-plant herbivore. Biodiversitas 20: 3499-3507. The present study has evaluated the indirect, top-down effects of a parasitoid wasp, Torymus beneficus Yasumatsu et Kamijo (Hymenoptera: Torymidae), of a gall-maker, Dryocosmus kuriphilus Yasumatsu (Hymenoptera: Cynipidae), on the characteristics of the chestnut tree, Castanea crenata Siebold \& Zucc. (Fagales: Fagaceae), and the implications for other herbivores, the aphid, Myzocallis kuricola (Matsumura) (Homoptera: Aphididae). sharing the same host plant. In a field experiment, the behavior of D. kuriphilus larvae on chestnut tree was influenced by the T. beneficus as indicated by a small increment of gall volume. However, parasitism did not affect certain other leaf characteristics that were induced by the gall wasp. Here we show that the characteristics of chestnut tree induced by the gall-making wasp affected M. kuricola that subsequently attacked the chestnut tree. However, the hypothesis that top-down effects by natural enemies may affect other herbivores on chestnut tree through its influence on gall-making wasp was not supported in this study. This study shows that parasitism of a gallmaker does not affect the other herbivore sharing the same host plant. Furthermore, the top-down effects of the parasitoid's behavior on plants may have different effects on sharing host herbivores that attack galled plants.
\end{abstract}

Keywords: Gall-making wasp, herbivores, induced response, parasitoid wasp, top-down effects

\section{INTRODUCTION}

The interaction between insects and plants is an important part of an ecosystem and a number of studies have examined the plant-based interactions system both at the molecular and ecosystem levels (Kessler and Baldwin 2002; Schuman and Baldwin 2016; Erb and Reymond 2019). Recently, research on plant-insect interactions has addressed not only the interactions between one plant and one insect species (Kessler and Baldwin 2002; Mithofer and Boland 2012) but also have reached up to community level (Ohgushi 2005; Poelman et al. 2011a, b). For defending herbivores, plants have evolved a variety of responses (plant induced responses) such as developmental (Damman 1989; Karban and Myers 1989;), phenological (Stephens and Westoby 2015; Oliveira et al. 2016), physical (Triyogo and Yasuda 2013), and chemical responses (Karban and Baldwin 1997; Poelman and Dicke 2018); and these responses in turn, may influence other insects other than herbivores, such carnivores Arthropoda that manage the population of herbivorous (Hilker and Meiners 2010; Mumm and Dicke 2010).

There have been several studies on the indirect interaction between plants and carnivores through herbivores-induced plant volatiles (Bonaventure et al. 2011; Aartsma et al. 2017; Frago et al. 2017; Xu et al. 2017). Under the plant induced responses to context, the presence of predator/parasitoid might change the responses of plants due to herbivores pressure. Previous studies have mentioned that the development of parasitoids within their herbivorous hosts, attacking a given host plant, may influence the reactions in the host plant (Poelman et al. 2011a; Cusumano et al. 2018). This may, in turn, affect the behavior of subsequent herbivores attacking the host plant, and thus, can have large effects on community composition at the second, third, and even higher trophic levels (Stam et al. 2014). Several studies have been conducted to investigate the modification of plant traits due to feeding damage, using herbivores belonging to different feeding guilds such as gall-making insects (Nakamura et al. 2003; Tewari et al. 2013; Triyogo and Yasuda 2013), leaf feeders (Vijaya and Rani 2017), sucking insects (Rani and Jyothsna 2010; da Silva et al. 2016), insect borers (Calderón-Cortés 2016), and phloem-feeders (Abbate et al. 2018). Yet most studies on direct or indirect defenses of plants against herbivory have treated herbivores as individual stressors. This issue was first conceptualized and was then applied in parasitoid system experiments in Poelman et al. (2011a, b). However, little information is available concerning how carnivorous insects influence plants trait indirectly by parasitizing herbivores that attack the plants (Poelman et al. 2011a, b; Stam et al. 2014).

In Japan, the invasive chestnut gall wasp Dryocosmus kuriphilus Yasumatsu (Hymenoptera: Cynipidae) is one of the most serious pests of chestnut trees (Castanea crenata Siebold \& Zucc.) (Moriya et al. 1989; Murakami 1997). Successful introductions of natural enemies to reduce $D$. kuriphilus populations have been reported (Piao and 
Moriya 1999). Torymus beneficus Yasumatsu et Kamijo (Hymenoptera: Torymidae) is a very common native parasitoid that has become dominant in attacking the invasive chestnut gall wasp (Murakami 1981; Kato and Hijii 1999; Wachi and Abe 2009). When combined with the closely related, introduced $T$. sinensis, $T$. beneficus is thought to be an effective biological control agent (Piao and Moriya 1999; Quacchia et al. 2008; Gibbs et al. 2011). To date, studies on T. beneficus have mainly focused on its behavior, population dynamics, and success as a natural enemy to control the population of $D$. kuriphilus on chestnut trees (Kato and Hijii 1999; Quachia et al. 2008; Wachi and Abe 2009). It has been reported that several leaf characteristics of $C$. crenata were altered as an induced response to attack by $D$. kuriphilus (Triyogo and Yasuda 2013). For example, the leaf nitrogen concentration in galled shoots was higher, while the leaf biomass was lower on galled shoot than that on ungalled shoots.

Here, we have designed the first field study to investigate the indirect effects of a native parasitoid wasp, $T$. beneficus, on the abundance and performance of an herbivore, the aphid, Myzocallis kuricola (Matsumura) (Homoptera: Aphididae) subsequently attacking the chestnut leaves. Such indirect effects might be expected (Triyogo and Yasuda 2013). Under the concept of interactions across three trophic levels, when a parasitoid parasitizes an herbivore, the parasitoid larva can affect the performance of the herbivore such that the herbivore interacts differently with the host plant (Poelman et al. 2011a). The hypothesis to be tested in this study is whether parasitism of $D$. kuriphilus indirectly affects the inducedresponses of the plant to the gall-maker, by directly affecting larvae of the D. kuriphilus. In particular, we address the following questions: (i) Does the parasitoid of D. kuriphilus change-induced responses of the host plant? (ii) How does the parasitoid of $D$. kuriphilus affect the abundance of subsequent herbivore aphids? and (iii) What are the impacts on different herbivores (aphids), of change in host quality resulting from parasitism of the gall-making insect?

\section{MATERIALS AND METHODS}

\section{Experimental design}

A field study was designed to observe the chain of interactions involving the parasitoid ( $T$. beneficus), the gall-making insect (D. kuriphilus), and another herbivore (the aphid, M. kuricola) on chestnut trees (C. crenata). Previous study indicated that galled chestnut leaves are altered nutritionally and morphologically. It was anticipated therefore that $D$. kuriphilus manipulation of the host plant would affect the performance of the other herbivore, M. kuricola. To include the third trophic level as part of the experimental design, releases of $T$. beneficus were made. There were three treatments included in the study. The treatments in this study consist of: (i) buds with only the gall-making insect present (G); (ii) buds with gallmakers parasitized by the parasitoid, T. beneficus, $(\mathrm{G}+\mathrm{P})$; and (iii) healthy buds with neither the gall-maker or the parasitoid present (control treatment).

\section{Study area and host plant}

This study was conducted in 2012 and 2013 at the Yamagata University Research Farm (384`N, 13949`E) in Tsuruoka, Yamagata Prefecture, Japan. The chestnut trees growing on this farm were surrounded by coniferous trees and fruit trees (several species). In this study area, chestnut trees were heavily attacked by the gall insect, $D$. kuriphilus, and more than $90 \%$ of galls were sessile (ballshaped) (Triyogo and Yasuda 2013). Previous study has shown that the highest numbers of galls per 1-year-oldshoot were 5 to 10 sessile galls, and 6 to 9 galls per shoot, on C. crenata var. Tsukuba in 2011 and 2012, respectively (Triyogo and Yasuda 2013). In this study, ten $C$. crenata var. Tsukuba (referred to T1-T10) with high numbers of galls caused by $D$. kuriphilus were selected as sample trees. Each tree was $2.5 \mathrm{~m}$ in height, and $80 \%$ of shoots on all sampled trees were attacked by gall-making insects. The galls develop in May in synchrony with the opening of current chestnut buds (Triyogo and Yasuda 2013). Observations in 2011 showed that the most common parasitoid wasp that attacked D. kuriphilus was $T$. beneficus. According to Murakami (1981), adults of $T$. beneficus emerge from withered galls on chestnut trees formed in the previous year, and females oviposit in newly formed galls. Among the most common herbivores that arrive and colonize the newly emerged leaves is the aphid $M$. kuricola. Large numbers of $M$. kuricola were found on C. crenata from spring to early autumn on shoots and leaves (Triyogo and Yasuda 2013).

\section{Bud sampling in the field}

In the present study, sampling of shoots began when galls could easily be found and before the emergence period of the parasitoid wasp. The sampling date was chosen based on observations made in 2011 that showed that in this study area, the adult of $T$. beneficus first emerged in late April. From ten sample trees (T1-T10), six galled shoots in 2012 and four galled shoots in 2013 were sampled on each tree. Therefore, in total, 60 and 40 shoots with newly formed galls were marked on 20 April 2012 and 22 April 2013, respectively. One gall from each of these galled shoots was chosen carefully making sure that all the selected galls have similar initial sessile gall volume (2012; $n=60$ galls, $F=1.64, p>0.05$ and 2013; $n=40$ galls, $F=0.09, p>0.05)$. The gall volume was estimated by the equation: gall volume $=4.189 \times$ length $/ 2 \times$ (avg. diameter $/ 2)^{2}$ (Flaherty and Quiring 2008). After measuring gall volume, the number of leaves initially present was counted. To prevent parasitism by $T$. beneficus, nylon-mesh bags were used to cover the sample galls on the shoot (Otake et al. 1984) and the bag was replaced following subsequent leaf growth.

\section{Collection and release of parasitoid wasp}

In order to obtain $T$. beneficus adult wasps for experimental release, 1,000 withered galls were collected from the study area in March 2012 and 2013. Sets of ten 
galls were placed into glass tubes (i.e., ten galls per tube) and kept refrigerated at $5{ }^{\circ} \mathrm{C}$ until the beginning of April. In total, 100 glass tubes plugged with cotton wool were used. At the beginning of April, in order to obtain the appropriate environmental conditions, these 100 tubes were transferred to outdoors. All the tubes were examined every 24 hours to collect emerging parasitoids during the period from 22 April to 9 May in 2012 and 22 April to 11 May in 2013. To ensure mating, each newly emerged $T$. beneficus female was placed with a male in a glass tube covered by cotton wool and supplied with drops of honey as food. The glass tubes used for mating were kept in an environmental chamber with L16: D8 photoperiod at $20{ }^{\circ} \mathrm{C}$. Daily video observation (Dino-Lite AM2011 digital microscope), was conducted to obtain mated females from these tubes. Soon after a mated female was obtained, the tube with this female was put inside a nylon-mesh bag. For the gall wasps plus parasitoid treatment $(\mathrm{G}+\mathrm{P})$, the cotton wool cover of the tube was removed to allow the parasitoid to disperse from the nylon-mesh bag. In 2012, mated females were released on 14 May (T1-T6), and 15 May (T7-T10). From 60 galled-buds prepared in April (see Bud sampling in the field), 30 galls with similar volume were used for the $G$ treatment (only gall wasps) and 30 galls for the G+P treatment (30 mated female parasitoids). Similar procedures were used to obtain the gall samples in 2013; 40 shoots with newly formed galls were selected. The parasitoid wasps, collected from dry galls in 2013, were released on 13 May. From 40 galled-buds, 20 galls were used for the $G$ treatment and 20 were used for the $\mathrm{G}+\mathrm{P}$ treatment. In addition, 30 normal buds designated as control were taken from the experiment conducted in 2012, while due to the low abundance of normal buds there was no control in 2013.

\section{Parasitoid wasp observation}

Galls were collected at different Days After Infestation (DAI) with parasitoid wasps from 2012 to 2013 (at three DAI in 2012 (15, 45, and 75 DAI) and two in 2013 (5 and 10 DAI). The successful introduction of released parasitoids to galls was confirmed from the presence of gall oviposition holes, and/or the presence of parasitoid eggs and larvae as well as parasitoid host-feeding tubes. All gall samples were measured for volume, number of chambers per gall, number of $D$. kuriphilus (parasitized and unparasitized larvae), and $T$. beneficus. In addition, the frequency distribution of parasitoid larvae per host larval chamber was determined. The gall samples were opened carefully to determine the age distribution of $T$. beneficus inside the gall from the developmental stages of individuals (eggs, young larvae, and mature larvae). All parasitoid observations were conducted in the laboratory using a dissecting microscope (Carton Stereo Microscope DSZ-44PG).

\section{Plant responses}

Field collections were done on three Days After Infestation (DAIs) $(15,45$, and 75) in 2012: the emerged leaves were harvested on 29-30 May, 29-30 June, and 2930 July as the first, second, and third harvest, respectively. In 2013, collections were done on two DAIs (5 and 10): first on 18 May, and again on 23 May. To determine the effects of the parasitoid wasp on gall volume for treatments $\mathrm{G}$ and $\mathrm{G}+\mathrm{P}$, the increase in gall volume was measured as the difference in volume between galls initially and at the time of harvest. In addition, increase in leaf number was estimated for treatments $\mathrm{G}, \mathrm{G}+\mathrm{P}$, and control, as the difference between number of leaves initially when wasps were released, and later at harvest time $(15,45$, and 75 DAI in 2012, and 5, 10 DAI in 2013). To assess nutritional characteristics, the leaves were then cut and separated into two groups; the first group was analyzed for nutritional properties (water content, nitrogen, and carbon concentration), and the second group was used in laboratory experiments. To examine the effects of each treatment on physical characteristics of the leaf, the leaf thickness and toughness were measured for those leaves that were subsequently analyzed for nutritional properties. Leaf weight was measured both as fresh weight and as dry weight after leaves were oven-dried at $70{ }^{\circ} \mathrm{C}$ for $48 \mathrm{~h}$. Percentage leaf water content was calculated as (fresh weight - dry weight)/fresh weight x 100 . The percentages of Nitrogen and Carbon concentration in a leaf was measured by using an elemental analyzer (NC Analyzer Sumigraph NC-220F) after the dried leaves had been ground. To measure leaf physical properties, 2 leaves were taken from the first group of leaves in treatments $G$ and $\mathrm{G}+\mathrm{P}$, and were compared with leaves from normal buds. A hand-held micrometer (PK-1012 Mitutoyo, Japan) was used to measure leaf thickness midway between the margin and midrib at the widest part of the leaf. Measurement of toughness was conducted three times at the midway point between the margin and the midvein by using a hand-held penetrometer (AD-4932-50N AND Inc., Japan).

\section{Effect of the parasitoid wasp on the abundance of herbivores}

Field observations and laboratory experiments were conducted to understand the effects of leaves from parasitized galls, unparasitized galls, and control buds, on the aphid. Field observations were conducted at the same time that galls were sampled to estimate aphid abundance. The number of aphids on all leaves attached to each sample gall was counted. Laboratory experiments were conducted to reveal the effects of leaves from each treatment on aphid performance. The leaves used were healthy leaves and have never been attacked by other insects previously. Laboratory-reared aphids were allowed to feed on the leaves from each treatment $(\mathrm{G}, \mathrm{G}+\mathrm{P}$, and control). Aphids were placed individually on a leaf and covered with a leaf cage $(1.5 \mathrm{~cm}$ in diameter and $8 \mathrm{~cm}$ in height) and were placed in an incubator with L16: D8 photoperiod at $20{ }^{\circ} \mathrm{C}$. Five leaves were used for each treatment. In total, 45 leaves were used from May to July 2012. The petioles of all leaves were individually inserted in a $1 \mathrm{ml}$ water pick and the water was replaced every day. The number of nymphs laid was monitored every day for six days. On the sixth day, the female aphid was then removed and the body weight was measured by using a microbalance (Sartorius MC 5, Max 5.1.g, and ISO 9001). 


\section{Statistical analyses}

The increase in gall volume between $\mathrm{G}$ and $\mathrm{G}+\mathrm{P}$ was compared by using the Mann-Whitney $U$ test. The differences in leaf characteristics, including leaf increment, thickness, toughness, water content, and $\mathrm{C}: \mathrm{N}$ ratio, for each gall treatment $(\mathrm{G}, \mathrm{G}+\mathrm{P}$, and control) and DAI were analyzed. Assumptions of normality and equal variance were met, and thus the data were analyzed by using repeated measures ANOVA to detect the effects of the three treatments on leaf characteristics. When significant differences among treatments were observed, analyses were continued by using Post hoc analysis with Tukey's test to compare the leaf characteristics among gall treatments and DAI. Following a similar procedure, the effects of gall treatment and DAI on the abundance, fecundity, and body weight decrease of aphids were determined by using two-way ANOVA and followed by Tukey`s post hoc test.

\section{RESULTS AND DISCUSSION}

\section{Parasitoid wasp and gall observation}

Four indications of interaction between gall-making larvae and its parasitoid wasp were found as follows: (a) hole on gall surface, (b) host-feeding tube, (c) eggs, and (d) larvae of parasitoid wasp (Figure 1). In a previous study, a feeding tube was found to be constructed for host-feeding by the parasitoid when attacking a gall wasp larva (Figure 1.B) (Kato and Hijii 1999).

In the present study, as DAI increased, so too did the maximum volume of galls and the number of chambers per gall (Table 1). The eggs of $T$. beneficus were found at 5 and 10 DAI, while young larvae were found at 15 DAI; moreover, observation at $15 \mathrm{DAI}$ indicated that $T$. beneficus was able to lay two eggs in a single gall chamber (Table 1). In contrast, only one parasitoid larva was found on each gall wasp larva at 45 and 75 DAI. Our results are supported by a previous study (Murakami and Tokuhisa 1985) in which the parasitoid had the capability to deposit two or more eggs in the same larval chamber. However, cannibalism among hatched young larvae in early stages for this parasitoid wasp has been reported (Murakami 1981;
Piao and Moriya 1999), and in the end, only one parasitoid larva could survive in each chamber.

Consistent with previous study, this study showed that, the gall larvae cause an increase in gall volume as the plant responded to gall-making larva, (Kato and Hijii 1993). On the other hand, our results showed the presence of young larvae of parasitoid wasp on it is host at 15 DAI, however, there was no significant effect on increase in gall volume until 15 DAI. In this study, we suspected that the parasitoid wasp would indirectly affect this increase in gall volume by affecting performance of the gall larvae. As described in previous research, when a parasitoid parasitizes an herbivore, the parasitoid larva affects performance of the herbivore (Poelman et al. 2011a). Our study further shows that parasite attack does not stop gall growth. However, the differences in the increase in gall volume were significant start at a month after 15 DAI (45 and 75 DAI) (Figure 2). The increase in gall volume in the $G$ treatment was significantly higher than that in the $\mathrm{G}+\mathrm{P}$ treatment at 45 and 75 DAI (Mann-Whitney $U$ test; 45 DAI $n G+P=7, n G$ $=10, U=5, p<0.001$; and $75 \mathrm{DAI} n G+P=8, n G=10, U$ $=0.5, p<0.001)$. Further, our results indicate that the parasitoid had an influence on young gall-making larvae, however, along with the gall-making larvae development, the effects of parasitoid begin to appear through the difference in gall volume (Table 2).

The presence of parasitoid ( $\mathrm{G}+\mathrm{P}$ treatment) resulted in a low gall volume increment as a consequence of decreased feeding rate and furthermore less inducement of increased gall volume by gall-making larvae. As mentioned earlier that the parasitoid/predator may cause change in host traits such as decrease in feeding rate and total food consumed of its host (Poelman et al. 2011a; Parkman and Shepard 1981; Powell 1989; Peckarsky et al. 2008). However, the increment of gall volume also occurred in the presence of parasitoids (Figure 2). Those, supported with previous study, larvae of $T$. beneficus feed as ectoparasites on the gall-making larva for a month after hatching (Murakami 1981; 1988), and our results indicated that T. beneficus allows the gall-making larva continues to feed during parasitoid development (koinobiont parasitoid) (Van Loon et al. 2000).

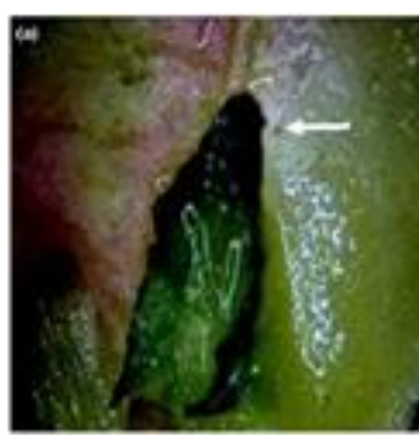

$\mathbf{A}$

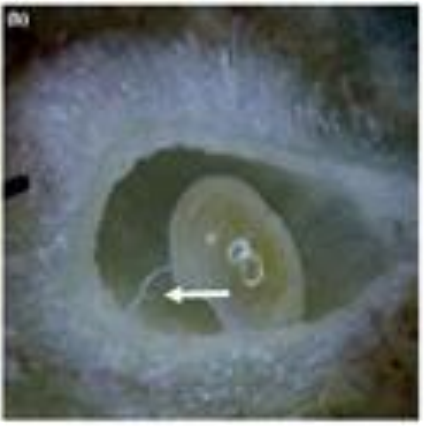

B

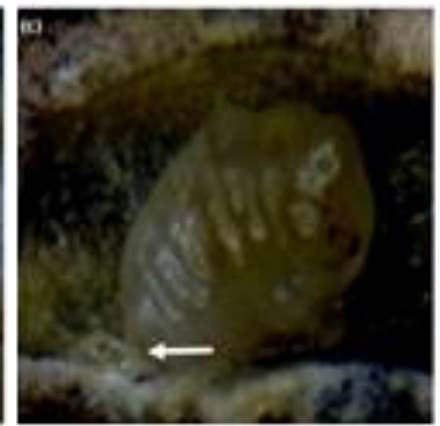

$\mathbf{C}$

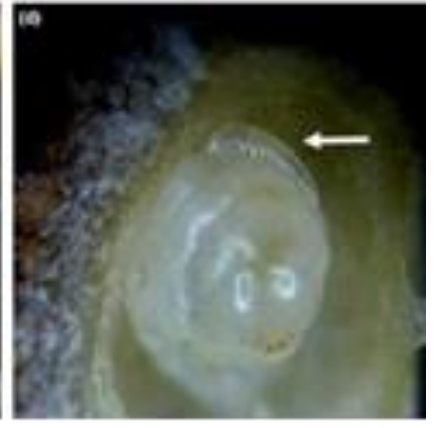

D

Figure 1. The symptoms indicating interactions between parasitoid and gall-making larvae (indicated by arrow). A. Hole made by the ovipositor of parasitoid wasp, B. Feeding tube, C. Eggs, D. Mature larva (All pictures were observed with 40X magnification) Note: A and B were found on 5 to $75 \mathrm{DAI}$; C was found on 5 and $10 \mathrm{DAI}$; D was found on $45 \mathrm{DAI}$. 
Table 1. The gall volume, number of chambers per gall, number of Dryocosmus kuriphilus and Torymus beneficus larvae, and number of parasitized D. kuriphilus observation on five different Day after infestation (DAI)

\begin{tabular}{lccccccc}
\hline \multirow{2}{*}{ DAI } & $\begin{array}{c}\text { No. of galls } \\
\text { examined }\end{array}$ & \multicolumn{2}{c}{ Vol. $\left(\mathbf{m m}^{\mathbf{3}}\right)$} & $\begin{array}{c}\text { Mean numbers of } \\
\text { chambers per gall (SD) }\end{array}$ & $\begin{array}{c}\text { Min. } \\
\text { D. } \text { kuriphilus } \text { larvae }\end{array}$ & $\begin{array}{c}\text { No. of } \\
\text { No. of } \text { T. beneficus }\end{array}$ & $\begin{array}{c}\text { No. of hosts } \\
\text { parasitized }\end{array}$ \\
\hline 5 & 10 & 0.80 & 2.31 & $5(0.96)$ & 54 & 30 (eggs) \\
10 & 10 & 0.70 & 2.20 & $7(0.99)$ & 71 & 9 (eggs); 21 (larvae) \\
15 & 10 & 0.51 & 1.41 & $5(0.73)$ & 51 & 41 (larvae) \\
45 & 10 & 0.50 & 2.46 & $7(1.79)$ & 71 & $15($ larvae) \\
75 & 10 & 0.68 & 2.67 & $7(2.00)$ & 68 & 21 (larvae) & 15 \\
\hline
\end{tabular}

Table 2. Results of repeated measure ANOVA for the effects of Galls and Day after infestation (DAI) on the increment of gall volume

\begin{tabular}{lcccc}
\hline Source & $\boldsymbol{d} \boldsymbol{f}$ & Mean Square & $\boldsymbol{F}$ value & $\boldsymbol{p}$ value \\
\hline Galls & 1 & 0.14 & 13.47 & $0.02 *$ \\
DAI & 2 & 0.11 & 10.05 & $0.00 * *$ \\
Galls * DAI & 2 & 0.07 & 5.29 & $0.00 * *$
\end{tabular}

Asterisks show significant difference $* p<0.05, * * p<0.01, * * *$ $p<0.001$

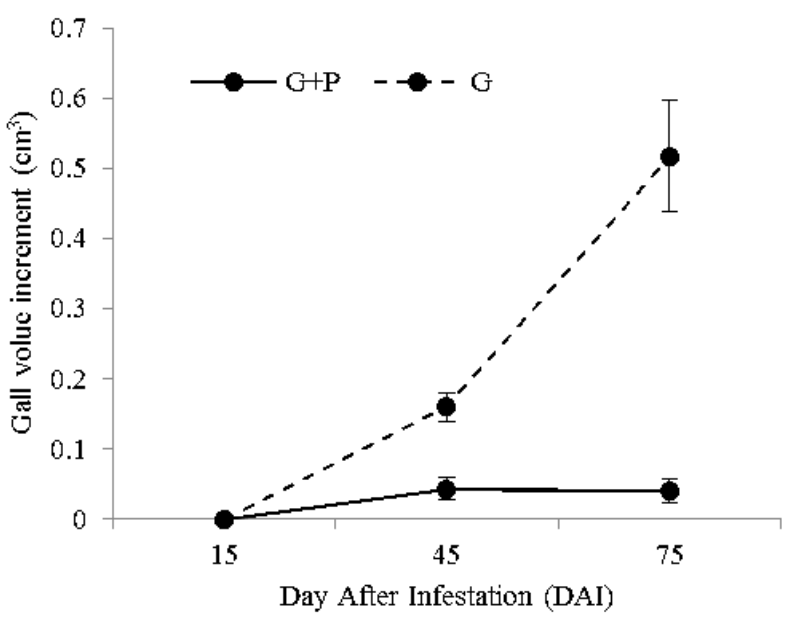

Figure 2 The gall volume increment. Mean and SE are presented. (G+P: Gall wasp plus parasitoid and G: Gall wasp only)

\section{Plant responses}

In field observations, there were significant effects of galling and DAI on leaf number increment (ANOVA: $p<$ 0.001) (Table 3). We found that the number of emerged leaf on galled treatment $(\mathrm{G}$ and $\mathrm{G}+\mathrm{P})$ was significantly higher than $\mathrm{C}$ in $15 \mathrm{DAI}$ but the opposite pattern on 45 and 75 DAI (Figure 3.A). Significant differences among treatments (galls and DAI) on leaf characteristics were observed (Table 3). We compared $\mathrm{G}$ vs $\mathrm{G}+\mathrm{P}$ vs $\mathrm{C}$ on the leaf characteristics with posthoc tests. However, Post-hoc tests showed no significant differences between $G$ vs $G+P$ treatments for all leaf characteristics (Figure 3.A-C) even when significant treatment effects were detected in 2-way ANOVA for galls variation (Table 3 ).

Under this study, we predicted that the presence of the parasitoid wasp would influence plant responses by affecting gall wasp larvae, but our prediction was not supported. One possibility to explain our results lies in the species of parasitoid we studied. Various parasitoid species differentially affect the interaction chain of parasitoid, herbivore host, and the host plant (Poelman et al. 2011a). It is well-known that behaviors of host insects such as feeding change after parasitism (Schmitz et al. 2004). As shown in this study, $T$. beneficus significantly inhibited the feeding rate of gall-making larvae (as reflected in gall volume at $45 \mathrm{DAI}$ ), however, the host larva still grew while parasitized (koinobiont species), and thus the plant did not benefit much from parasitism of the gall-maker. Secondly, the parasitoid studied here lives externally on its host's body (ectoparasitoid) with a single parasitoid larva per herbivore host might have weak pressure. Previous study has focused on parasitism explained that the parasite diversity per herbivore host considers as potential determining factor for estimating parasite pressures and impacts on host (Bordes and Morand 2009).

Table 3. Results of repeated measure ANOVA for the effects Galls, Day after infestation (DAI), and their interactions on the leaf characteristic

\begin{tabular}{|c|c|c|c|c|c|c|}
\hline \multirow[b]{2}{*}{$\begin{array}{l}\text { Source of } \\
\text { variation }\end{array}$} & \multirow[b]{2}{*}{$d f$} & \multicolumn{5}{|c|}{$F$ value } \\
\hline & & $\begin{array}{l}\text { Leaf number } \\
\text { increment }^{\text {(a) }}\end{array}$ & $\begin{array}{c}\text { Thickness } \\
\text { (mm) }\end{array}$ & $\begin{array}{c}\text { Toughness } \\
\text { (N) }\end{array}$ & $\begin{array}{c}\text { Water } \\
\text { content }(\% \mathrm{DW})\end{array}$ & CN ratio \\
\hline Galls & 2 & $5.833^{*}$ & $3.769 \mathrm{~ns}$ & $3.607 \mathrm{~ns}$ & $0.214 \mathrm{~ns}$ & $0.455 \mathrm{~ns}$ \\
\hline DAI & 4 & $68.076 * * *$ & $8.013^{*}$ & $3.870^{*}$ & $12.366^{*}$ & $18.634 * *$ \\
\hline Galls x DAI & 8 & $2.987 * * *$ & $1.791 \mathrm{~ns}$ & $2.045 \mathrm{~ns}$ & $2.956 \mathrm{~ns}$ & $0.597 \mathrm{~ns}$ \\
\hline
\end{tabular}


Note: The numbers were counted from the first release of the parasitoid wasp Asterisks show significant difference $* p<0.05, * * p<$ $0.01, * * * p<0.001$, and ns shows no significant at $p>0.0$

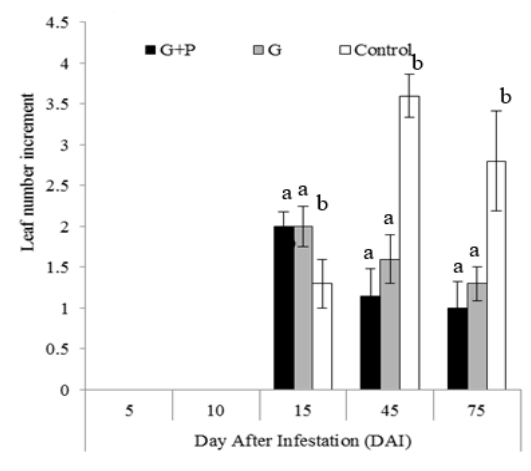

A

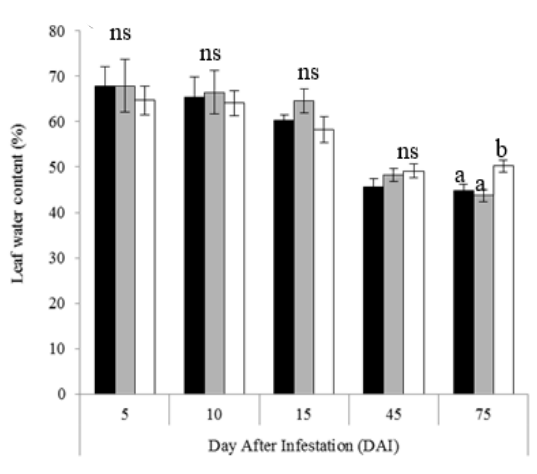

B

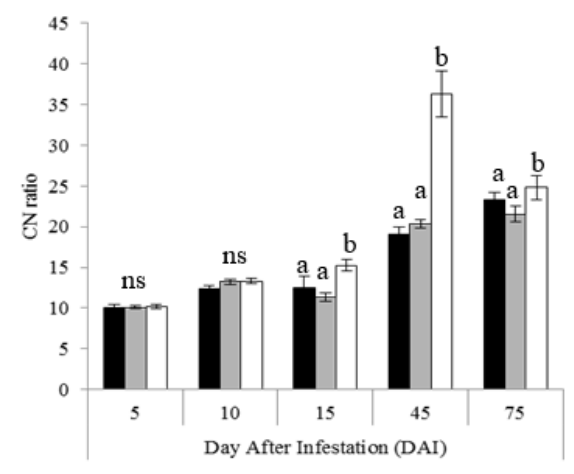

C

Figure 3. The Post-hoc results for leaf characters between three different treatments which were harvested on five different DAI. A. Leaf number increment, B. Leaf water content, C. CN ratio. Mean and SE are presented. Different letters show significant difference ( $p$ $<0.05$, Tukey`s test) and ns shows no significant at $p>0.05$

Another possibility to explain our results is a lack of synchrony between gall-making larval development and the annual period of activity of the parasitoid wasp. In this study area, the gall-making adults emerge and soon begin to lay eggs in July inside chestnut buds that will develop during the next spring. Hatching begins one month after oviposition, and the hatched larvae remain in the buds and continue overwintering inside the gall. After overwintering, the larvae of the gall-making insects become active in early May (Triyogo and Yasuda 2013). The period of larval activity is synchronized with the opening of chestnut buds, and thereafter infested buds turn into galls in the spring (Kato and Hijii 2001; Piao and Moriya 1999). In our study area, there was about an 8-month lag between the emergence of $T$. benefices and the hatch of first instar $D$. kuriphilus. It has been reported that the single species $T$. benefices alone failed to suppress the pest population (Murakami 1997) until a second, introduced parasitoid, $T$. sinensis, was released (Moriya et al. 1989).

Based on the two possibilities mentioned in this discussion, the pressure of parasitoid larvae attacking the gall-making larvae gives different results from our hypothesis. Thus, in the present study, the induced responses of $C$. crenata plants, as expressed in leaf characteristics, did not differ in response to feeding by unparasitized versus parasitized gall-making larvae.

\section{Effects on subsequent herbivores}

We studied the number of aphids, M. kuricola, as another herbivore sharing the host plant with the gallmaking wasp. The colonies of this aphid on leaves were first encountered at 15 DAI. The number of aphids was higher on emerged leaves in treatments $G$ (8.10 individual numbers) and $\mathrm{G}+\mathrm{P}$ (7.37) than in the control treatment (5.90) at 15 DAI. On the other side, at 75 DAI results were reversed from 15 DAI, with high number of aphid in the control treatment (7.10) than in treatments $\mathrm{G}+\mathrm{P}(6.12)$ and $\mathrm{G}$ (4.60) (Figure 4).
In accordance with our previous study, the effect of the gall insect on aphid abundance was most pronounced early in the season. Generally, the number of aphid on leaves declined overtime on galled-leaves $(\mathrm{G} ; \mathrm{G}+\mathrm{P})$ and increased on healthy (control) leaves. Previous study has shown that new leaves emerged earlier on galled leaves, and aphids tended to find and feed on the young leaves (Triyogo and Yasuda 2013). The presence of the parasitoid in the present study did not significantly affect the number of aphids. Indirect effects by parasitoids on community composition will occur when parasitoids through top-down effects influence herbivores, thereby inducing modification in host plant characteristics (Ohgushi et al. 2012; Poelman et al. 2011a). In our laboratory experiment, the aphid females produced more nymphs and weighed more in treatments $G$ and $\mathrm{G}+\mathrm{P}$ than in control until 45 DAI but these results were reversed on 75 DAI (Figure 4). On each DAI, however, there were no significant differences in any aphid parameters between G vs G+P (Table 4; Figure 4).

Previous study has revealed that when a parasitoid strongly affected herbivore-host plant interactions, the parasitoid also played an important role in affecting reproductive fitness of other herbivorous insects attacking the host plant (Tooker and Hanks 2006). Despite the difference observed in this study in the rate of increase in gall volume, there was no significant improvement in quality overall of leaf characteristics; furthermore, we noted that there were no statistically significant differences in aphid abundance and performance between $\mathrm{G}$ and $\mathrm{G}+\mathrm{P}$ (Table 4). This result indicated that the effects of the parasitoid wasp in changing leaf characteristics might be weak given that the number of gall wasp larvae was high. As shown by our field observations that there were no galls with $100 \%$ parasitism of gall larvae inside the gall (Table 1). The numbers of gall-making larvae and low host parasitization on each gall seem to have an effect on an insignificant difference in leaf characteristics between $G$ and $\mathrm{G}+\mathrm{P}$ treatment. 


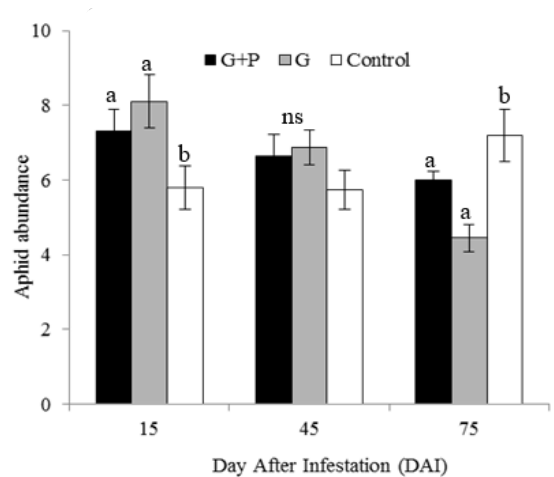

A

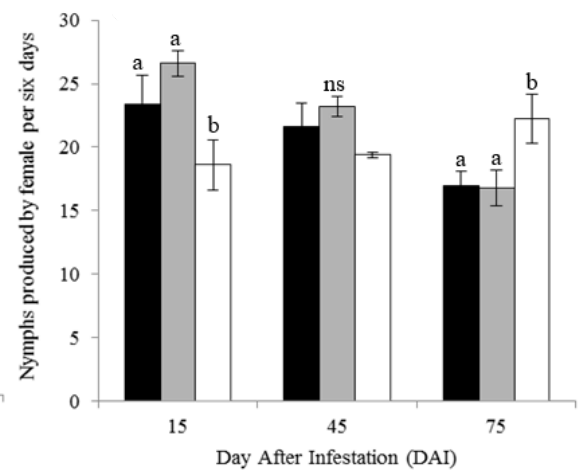

B

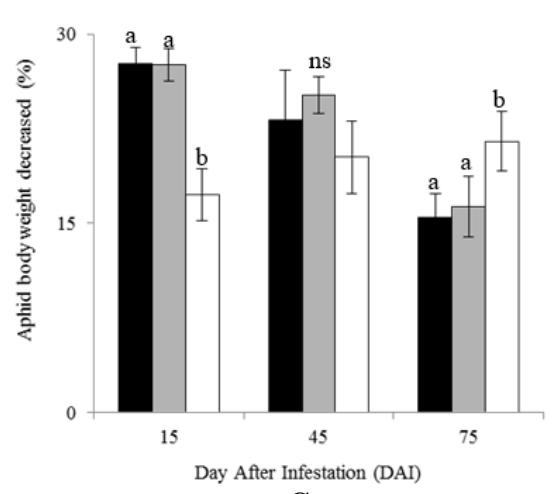

C

Figure 4 The Post-hoc results for aphid performances between three different treatments that were harvested on three different DAI. A. Aphid abundance, B. Nymphs produce by females per six days, C. Aphid body weight decreased. Mean and SE are presented. Different letters show significant difference ( $p<0.05$, Tukey`s test) and ns shows no significant at $p>0.05$.

Table 4. The results of two-way ANOVA for the effects of Galls and Day after infestation (DAI) on aphid performances

\begin{tabular}{lcccc}
\hline \multirow{2}{*}{$\begin{array}{c}\text { Source of } \\
\text { variation }\end{array}$} & $\boldsymbol{d f}$ & \multicolumn{3}{c}{$\boldsymbol{F}$ value } \\
\cline { 3 - 5 } & abundance & $\begin{array}{c}\text { Aphid } \\
\text { fecundity }\end{array}$ & $\begin{array}{c}\text { Bodyweight } \\
\text { decrease }\end{array}$ \\
\hline Galls & 2 & $2.148 \mathrm{~ns}$ & $1.603 \mathrm{~ns}$ & $1.844 \mathrm{~ns}$ \\
DAI & 2 & $3.845^{*}$ & $10.387^{* *}$ & $4.814^{*}$ \\
Galls * DAI & 4 & $2.550^{*}$ & $6.958^{* *}$ & $2.572^{*}$
\end{tabular}

Note: Asterisks show significant difference $* p<0.05, * * p<0.01$, , and ns shows no significant at $p>0.05$

In conclusion, the parasitoid larva affects performance of the herbivore such that, as a result, the herbivore interacts differently with the host plant. The gall maker, $D$. kuriphilus, is able to manipulate host plant quality; however, the endemic parasitoid wasp of gall-making insects on chestnut trees does not affect plant performance by attacking larvae of the gall wasp. Our study provides a simple model system illustrating the possibilities when the third trophic level does not affect plant-induced responses to a particular herbivore. The gall insect directly affects host plant quality and through bottom-up process, this affects the aphid performance. In addition, the parasitoid wasp affected the gall maker by reducing the seasonal increase in gall volume. However, the presence of the parasitoid wasp did not affect the interaction between the herbivore and the host plant. Moreover, herbivores as mediators between plant traits and predators or parasitoids did not have large effects on other herbivores sharing same host plant at the second trophic level. We presented several considerations to explain those results: (i) the characteristics of parasitoid used (koinobiont ectoparasitoid); (ii) poor synchronization between initial plant responses to the gall insect, and the interaction of parasitoid wasp and gall insect; and (iii) high abundance of gall wasp larvae.

\section{ACKNOWLEDGEMENTS}

We thank Prof. Edward Evans (Utah State University, USA) for helpful comments and for improving the English. We also thank anonymous reviewers for their valuable suggestions,

\section{REFERENCES}

Abbate C, Toscano S, Arcidiacono R, Romano D, Russo A, Mazzeo G. 2018. Induced responses of Bougainvillea glabra Choisy (Nyctaginaceae) against Phenacoccus peruvianus Granara de Willink (Hemiptera: Pseudococcidae) attack: preliminary results. ArthropodPlant Interact 12: 41-48. DOI: 10.1007/s11829-017-9550-4

Aartsma Y, Bianchi FJ, van der Werf W, Poelman EH, Dicke M. 2017. Herbivore-induced plant volatiles and tritrophic interactions across spatial scales. New Phytol 216 (4): 1054-1063. DOI: 10.1111/nph.14475

Bonaventure G, VanDoorn A, Baldwin IT. 2011. Herbivore-associated elicitors: FAC signaling and metabolism. Trends Plant Sci 16: 294299. DOI: 10.1016/j.tplants. 2011.01. 006

Calderón-Cortés N, Uribe-Mú CA, Martínez-Méndez AK, EscaleraVázquez LH, Cristobal-Pérez EJ, García-Oliva F, Quesada M. 2016. Ecosystem engineering and manipulation of host plant tissues by the insect borer Oncideres albomarginata chamela. J Insect Physiol 84: 128-136. DOI: 10.1016/j.jinsphys.2015.10.008

Cusumano A, Zhu F, Volkoff AN, Verbaarschot P, Bloem J, Vogel H, Dicke M, Poelman EH. 2018. Parasitic wasp-associated symbiont affects plant-mediated species interactions between herbivores. Ecol Lett 21 (7): 957-967. DOI: 10.1111/ele.12952

Damman H. 1989. Facilitative interactions between two lepidopteran herbivores of Asimina. Oecologia 78 (2): 214-219

Da Silva SE, França JF, Pareja M. 2016. Olfactory response of four aphidophagous insects to aphid-and caterpillar-induced plant volatiles. Arthropod-Plant Inte 10 (4): 331-340. DOI: 10.1007/s11829-0169436-x

Erb M, Reymond P. 2019. Molecular interactions between plants and insect herbivores. Ann Rev Plant Biol 70: 527-557. DOI: 10.1146/annurev-arplant-050718-095910

Flaherty L, Quiring D. 2008. Plant module size and dose of gall induction stimulus influence gall induction and galler performance. Oikos 117 (11): 1601-1608. DOI: 33410.HH/i.1600-0706.2008.16555.x

Frago E, Mala M, Weldegergis BT, Yang C, McLean A, Godfray HCJ, Gols R, Dicke M. 2017. Symbionts protect aphids from parasitic wasps by attenuating herbivore-induced plant volatiles. Nat Commun 8 (1): p1860. DOI: 10.1038/s41467-017-01935-0 
Gibbs M, Schönrogge K, Alma A, Melika G, Quacchia A, Stone GN, Aebi A. 2011. Torymus sinensis: a viable management option for the biological control of Dryocosmus kuriphilus in Europe?. BioControl 56 (4): 527-538. DOI: 10.1007/s10526-340011-9364-8

Hare JD. 2011. Ecological role of volatiles produced by plants in response to damage by herbivorous insects. Ann Rev Entomol 56: 161-180. DOI: 10.1146/annurev-ento-120709-144753

Hilker M, Meiners T. 2010. How do plants "notice" attack by herbivorous arthropods?. Biolo Rev 85 (2): 267-280. DOI: 10.1111/j.1469185X.2009.00100.x

Hunter MD, Price PW. 1992. Playing chutes and ladders: Heterogeneity and relative roles of bottom-up and top-down forces in natura communities. Ecology 73 (3): 724-732.

Karban R, Baldwin IT. 1997. Induced responses to herbivory. University of Chicago Press, Chicago, IL.

Karban R. 2011. The ecology and evolution of induced resistance against herbivores. Funct Ecol 25 (2): 339-347. DOI: 10.1111/j.13652435.2010.01789.x

Karban R, Myers JH. 1989. Induced plant responses to herbivory. Ann Rev Ecol Syst 20 (1): 331-348.

Kato K, Hijii N. 1993. Optimal clutch size of the chestnut gall-wasp, Dryocosmus kuriphilus Yasumatsu (Hymenoptera: Cynipidae). Res Popul Ecol 35: 1-14. DOI: 10.1007/BF02515640

Kato K, Hijii N. 1999. Mortality factors of the chestnut gall-wasp, Dryocosmus kuriphilus Yasumatsu (Hymenoptera: Cynipidae) afte gall formation. Entomol Sci 2 (4): 483-491

Kato K, Hijii N. 2001. Ovipositional traits of the chestnut gall wasp, Dryocosmus kuriphilus (Hymenoptera: Cynipidae). Entomol Sci 4 (3): 295-299.

Kessler A, Baldwin IT. 2002. Plant responses to insect herbivory: the emerging molecular analysis. Ann Rev Plant Biol 53 (1): 299-328. DOI: 10.1146/annurev.arplant.53.100301.135207.

Mithöfer A, Boland W. 2012. Plant defense against herbivores: chemical aspects. Ann Rev Plant Biol 63: 431-450. DOI: 10.1146/annurevarplant-042110-103854.

Miyashita K, Ito Y, Nakamura K, Nakamura M, Kondo M. 1965. Population dynamics of the chestnut gall wasp Drycosmus kuriphilus Yasumatsu (Hymenoptera: Cynipidae). III. Five years of observation on population fluctuation. Appl Entomol Zool 9: 42-52

Moriya S, Inoue K, Otake A, Shiga M, Mabuchi M. 1989. Decline of the chestnut gall wasp population, Dryocosmus kuriphilus Yasumatsu (Hymenoptera: Cynipidae) after the establishment of Torymus sinensis Kamijo (Hymenoptera: Torymidae). Appl Entomol Zool 24 (2): 231-233

Mumm R, Dicke M. 2010. Variation in natural plant products and the attraction of bodyguards involved in indirect plant defense. Can Zool 88 (7): 628-667. DOI: 10.1139/Z10-032.

Murakami Y. 1981. The Parasitoids of Dryocosmus kuriphilus Yasumatsu (Hymenoptera: Cynipidae) in Japan and the introduction of a promising natural enemy from China (Hymenoptera: Chalcidoidea). J Fat Agr 25 (4): 167-174

Murakami Y, Tokuhisa E. 1985. Behavioural sequences of oviposition and host-feeding of Torymus (Syntomaspis) beneficus Yasumatsu et Kamijo (Hymenoptera: Torymidae), a native parasitoid of Dryocosmus kuriphilus Yasumatsu (Hymenoptera: Cynipidae). Appl Entomol Zool 20 (1): 43-49.

Murakami Y. 1988. Ecotypes of Torymus (Syntomaspis) beneficus Yasumatsu et Kamijo (Hymenoptera: Torymidae) with differen seasonal prevalence of adult emergence. Appl Entomol Zool 23: 8187. DOI: $10.1303 / \mathrm{aez} .23 .81$

Murakami Y. 1997. Natural enemies of the chestnut gall wasp. approaches to biological control. Kyusyu University Press, Fukuoka. [Japanese]

Nakamura M, Miyamoto Y, Ohgushi T. 2003. Gall initiation enhances the availability of food resources for herbivorous insects. Funct Ecol 17 (6): $851-857$

Ohgushi T. 2005. Indirect interaction webs: herbivore-induced effects through trait change in plants. Ann Rev Ecol Evol Syst 36: 81-105. DOI: 10.1146/annurev.ecolsys. 36.091704. 175523.

Ohgushi T, Craig TP, Price PW. 2007. Ecological Communities: Plant Mediation in Indirect Interaction Webs. Cambridge University Press. Cambridge, UK

Ohgushi T, Schmitz OJ, Holt RD. 2012. Trait-Mediated Indirect Interactions: Ecological and Evolutionary Perspectives. Cambridge University Press, Cambridge, UK

Oliveira DC, Isaias RMS, Fernandes GW, Ferreira BG, Carneiro RGS, Fuzaro L. 2016. Manipulation of host plant cells and tissues by gall- inducing insects and adaptive strategies used by different feeding guilds. J Insect Physiol 84: 103-113. DOI: 10.1016/j.jinsphys.2015.11.012

Otake A. 1980. Chestnut gall wasp, Dryocosmus kuriphilus Yasumatsu (Hymenoptera: Cynipidae): A preliminary study on trend of adult emergence and some other ecological aspects related to the final stage of its lifecycle. Appl Entomol Zool 15: 829-839

Ôtake A, Moriya S, Shiga M. 1984. Colonization of Torymus sinensis Kamijo (Hymenoptera: Torymidae), a parasitoid of the chestnut gall wasp, Dryocosmus kuriphilus Yasumatsu (Hymenoptera: Cynipidae), introduced from China. Appl Entomol Zool 19: 111114

Parkman P, Shepard M. 1981. Foliage consumption by yellow striped armyworm larvae after parasitisation by Euplectrus plathypenae. Fla Entomol 64: 192-194.

Peckarsky BL, Abrams PA, Bolnick DI, Dill LM, Grabowski JH, Luttbeg B, Orrock JL, Peacor SD, Preisser EL, Schmitz OJ, Trussell GC. 2008. Revisiting the classics: considering nonconsumptive effects in textbook examples of predator-prey interactions. Ecology 89 (9): 2416-2425.

Piao CS, Moriya S. 1999. Oviposition of Torymus sinensis Kamijo (Hymenoptera: Torymidae) under natural conditions. Entomol Sci 2: 329-334

Poelman EH, Zheng SJ, Zhang Z, Heemskerk NM, Cortesero AM, Dicke M. 2011a. Parasitoid-specific induction of plant responses to parasitized herbivores affects colonization by subsequent herbivores. Proc Natl Acad Sci USA 108: 19647-19652. DOI: 10.1073/pnas.1110748108

Poelman EH, Gols R, Snoeren TA, Muru D, Smid HM, Dicke M. 2011 b. Indirect plant-mediated interactions among parasitoid larvae. Ecol Lett 14 (7): 670-676. DOI: 10.1111/j.1461-0248.2011.01629.x.

Poelman EH, Dicke M. 2018. Insect-Plant Interactions Section III. Ecology and Evolution of Insect-Plant Interactions. Ann Plant Rev 47: 309-337. DOI: 10.1002/9781119312994.apr0513.

Powell JE. 1989. Food consumption by tobacco budworm (Lepidoptera: Noctuidae) larvae reduced after parasitization Microplitis demolitor or M. croceipes (Hymenoptera: Braconidae). J Econ Entomol 82 (2): 408-411. DOI: $10.1093 /$ jee/82.2.408

Price PW, Bouton CE, Gross P et al. 1980 Interactions among three trophic levels: Influence of plants on interactions between insect herbivores and natural enemies Ann Rev Ecol Syst 11: 41-65. DOI: 10.1146/annurev.es.11.110180.000353.

Quacchia A, Moriya S, Bosio G, Scapin I, Alma A. 2008. Rearing, release and settlement prospect in Italy of Torymus sinensis, the biological control agent of the chestnut gall wasp Dryocosmus kuriphilus. Biocontrol 53: 829-839. DOI: 10.1007/s13355-013-0194-2.

Rani PU, Jyothsna Y. 2010. Biochemical and enzymatic changes in rice plants as a mechanism of defense. Acta Physiol Plant 32 (4): 695-701. DOI: $10.1007 / \mathrm{s} 11738-009-0449-2$

Schuman MC, Baldwin IT. 2016. The layers of plant responses to insect herbivores. Ann Rev Entomol 61: 373-394. DOI: 10.1146/annurevento-010715-023851

Schmitz OJ, Krivan V, Ovadia O. 2004. Trophic cascades: the primacy of trait-mediated indirect interactions. Ecol Lett 7 (2): 153-163. DOI: 10.1111/j.1461-0248.2003. 00560.x

Stam JM, Kroes A, Li Y et al. 2014. Plant interactions with multiple insect herbivores: From community to genes. Annu Rev Plant Biol 65: 689713. DOI: 10.1146/annurev-arplant-050213-035937 Stephens AE, Westoby M. 2015. Effects of insect attack to stems on plant survival, growth, reproduction and photosynthesis. Oikos 124 (3): 266-273. DOI: $10.1111 /$ oik.01809

Tewari S, Buonaccorsi JP, Averill AL. 2013. Impact of early season apical meristem injury by gall inducing tip worm (Diptera: Cecidomyiidae) on reproductive and vegetative growth of cranberry. J Econ Entomol 106 (3): 1339-1348. DOI: 10.1603/EC12269

Tooker JF, Hanks LM. 2006. Tritrophic interactions and reproductive fitness of the prairie perennial Silphium laciniatum Gillette (Asteraceae). Environ Entomol 35: 537-545. DOI: 10.1603/0046225X-35.2.537

Triyogo A, Yasuda H. 2013. Effect of host-plant manipulation by a gallinducing insect on abundance of herbivores on chestnut trees. Appl Entomol Zool 48 (3): 345-353. DOI: 10.1007/s13355-013-0194-2

Van Loon JJA, de Boer JG, Dicke M. 2000. Parasitoid-plant mutualism: parasitoid attack of herbivore increases plant reproduction. Entomol Exp Appl 97: 219-227

Vijaya M, Rani PU. 2017. Defensive responses in Capsicum annuиm (L) 
plants, induced due to the feeding by different larval instars of Spodoptera litura (F). Arthropod-Plant Interact 11 (2): 193-202. DOI: 10.1007/s11829-016-9479-z

Wachi N, Abe Y. 2009. Taxonomic status of the oak gall wasp Callirhytis hakonensis Ashmead (Hymenoptera: Cynipidae), a candidate for native host of Torymus beneficus Yasumatsu et Kamijo (Hymenoptera: Torymidae), with a description of its sexua generation. In: Moriya S (ed.) A Global Serious Pest of Chestnut
Trees, Dryocosmus kuriphilus: Yesterday, Today and Tomorrow. Proceedings of the Japan-Italy Joint International Symposium, Tsukuba, Japan, November 24-25, 2009.

Xu H, Desurmont G, Degen T, Zhou G, Laplanche D, Henryk L, Turlings TC. 2017. Combined use of herbivore-induced plant volatiles and sex pheromones for mate location in braconid parasitoids. Plant Cell Environ 40 (3): 330-339. 